\title{
PENDEKATAN CONTEXTUAL TEACHING AND LEARNING (CTL) UNTUK MENINGKATKAN HASIL BELAJAR AKIDAH AKHLAK
}

\author{
Binti Khoiriyah $^{*}$ ' Nur Laili 2 ' Masrurotul Mahmudah 3 \\ IAIMNU METRO LAMPUNG \\ Email: ${ }^{1}$ khoiriyahmaliki@gmail.com, ${ }^{2}$ Lnur81760@gmail.com, ${ }^{3}$ Mahmudahmasrurotul1@gmail.com
}

\begin{abstract}
This study was conducted for the purpose of know the application of approach CTL in their experiences of the results of grade 5 on student Akidah Akhlak in MIMU Tulung Jaya Sukadana east Lampung . The research is research the act of class . The collection of data using technique, observation, a test, interviews and documentation .This study was conducted in 2 cycles with every cycle 2 meeting. The subject of study this is students grade 5 MIMU Tulung Jaya with the number of 23 students on Akidah Akhlak. The result of this research showing that in learning by applying approach CTL study results students increased this cycle visible on student learning I the result was completeness $65,22 \%$ and on cycle II to achieve $86,95 \%$. I to cycle cycle II increased by $21,73 \%$.So that it can be analyzed that that the implementation of the approach CTL in learning activities can improve learning outcomes students grade 5 MIMU Tulung Jaya on the subjects Akidah Akhlak.
\end{abstract}

Penelitian ini dilaksanakan dengan tujuan untuk mengetahui penerapan pedekatan $C T L$ dalam pembelajaran terhadap hasil belajar siswa kelas $\mathrm{V}$ pada mata pelajaran Akidah Akhlak di MIMU Tulung Jaya Sukadana Lampung Timur. Penelitian ini merupakan penelitian tindakan kelas. Pengumpulan data menggunakan tehnik, observasi, tes, wawancara dan dokumentasi. Penelitian ini dilaksanakan dalam 2 siklus dengan setiap siklusnya 2 kali pertemuan. Subjek penelitian ini adalah siswa kelas V MIMU Tulung Jaya dengan jumlah 23 siswa pada matapelajaran Akidah Akhlak. Hasil penelitian ini menujukan bahwa dalam pembelajaran dengan menerapkan pendekatan CTL hasil belajar siswa mengalami peningkatan hal ini terliahat Pada siklus I hasil belajar siswa mencapai ketuntasan 65,22 \% dan pada siklus II mencapai 86,95\%. siklus I ke siklus II mengalami peningkatan sebesar $21,73 \%$. Sehingga dapat dianalisis bahawa bahwa penerapan pendekatan CTL dalam kegiatan pembelajaran dapat meningkatkan hasil belajar siswa kelas V MIMU Tulung Jaya pada mata pelajaran akidah akhlak.

Keyword: pendekatan Contextual Teaching and Learning, hasil belajar akidah akhlak

\section{A. PENDAhuluan}

Ketika kita membicarakan tentang masalah pendidikan di negeri ini pasti tidak ada habisnya karena banyak sekali permasalahan yang terjadi baik dalam birokrasi sampai pada permasalahan internal dalam pembejaran itu sendiri. Menurut undang undang no. 20 tahun 2013 pasal 3 yang berbunyi bahwa pendidikan nasional memiliki fungsi untuk meningkatkan kemampuan dan menciptakan moral bangsa yang beradab dan bermartabat yang bertujuan untuk mencerdaskan kehidupan bangsa, serta memiliki tujuan untuk mengembangakan kemampuan siswa supaya menjadi manusia yang beriman dan bertakwa kepada Tuhan Yang Maha Esa, 
berakhlak mulia, sehat, berilmu, cakap, kreatif, mandiri, dan bertanggung jawab serta menjadi warga negara yang baik dengan menaati hukum yang ada. ${ }^{1}$

Berdasarkan peraturan pemerintah uu no.20 tahun 2003 menyatakan bahwa pelajaran akidah akhlak mempunyai peran penting dalam tercapainya tujuan pendidikan nasional di Indonesia, menciptakan manusia yang taat kepada tuhan yang maha esa dan ber akhlak mulia. Pendidikan agama dapat menjadi salah satau faktor berhasil tidaknya pendidikan di indonesia. Akan tetapi dalam pelaksanan di lapanganya pendidikan agama terutama akidah akhlak masih banyak yang menekankan pada aspek kognitif, bukan pada aspek afektif dan psikomotorik, sehingga mengakibatakan siswa hanya dapat mengerti tentang agama akan tetapai hanya sebatas teori dan belum sampai pada aksi atau implementasi dalam kehidupannya sehari hari.

Dari hasil observasi dan wawancara yang dilakukan peneliti dengan guru mata pelajaran Akidah Akhlak MIMU Tulung Jaya, rendahnya hasil belajar matapelajaran Akidah Akhlak tersebut merupakan wujud dari berbagai masalah yang muncul dari kegiatan pembelajaran, diantaranya adalah akibat dari aktivitas siswa ketika mengikuti pembelajaran yang rendah. Aktivitas belajar siswa seperti memperhatikan guru ketika menerangkan meteri pelajaran, mengajukan pertanyaan di kelas V MIMU pada mata pelajaran Akidah Akhlak masih rendah. Rendahnya aktivitas belajar siswa tersebut disebabkan karena penerapan metode pembelajaran yang kurang sesuai dengan materi pelajaran, dan pengelolaan kelas yang belum maksimal mengakibatkan siswa kurang aktif. Siswa masih menganggap pelajaran Akidah Akhlak sebagai pelajaran yang sulit dan siswa belum mampu utuk mengamalkan dalam kehidupan sehari-hari sehingga tujuan pembelajaran belum tercapai dengan maksimal yang mengakibatkan hasil belajar siswa rendah tidak semua hasil belajar siswa mencapai KKM. Metode pembelajaran yang diterapkan masih belum bervariasi dan guru masih lebih aktif dari pada siswa.

Melihat permasalahan tersebut, maka digunakan Pendekatan CTL yang diharapkan dapat mengatasi masalah tersebut, dapat menarik perhatian siswa agar proses pembelajaran jadi menyenangkan. Pada dasarnya usaha guru dengan menerapkan Pendekatan CTL agar tujuan pembelajaran pembelajaran dapat tercapai. Disamping itu Pendekatan CTL dapat membuat pembelajaran menjadi lebih jelas dan kongkrit serta mudah dipahami oleh siswa karena dalam pembelajaran siswa memahami materi melalui pengalamannya sendiri. Dengan demikaian diharapkan dapat tercapai aktivitas belajar yang efektif.

Dari penjelasan sebelumnya maka dapat di peroleh kesimpulan bahwa penerapan Pendekatan CTL merupakan pendekatan pembelajaran Akidah Akhlak yang diharapkan bisa meningkatkan hasil belajar siswa. Oleh karena itu perlu diadakannya penelitian tindakan kelas untuk membuktikan bahwa melalui penerapan pendekatan CTL dalam pembelajaran dapat meningkatan hasil belajar siswa pada pelajaran Akidah Akhlak. Tujuan penelitian ini adalah Untuk mengetahui penerapan pedekatan CTL dalam pembelajaran terhadap hasil belajar siswa kelas V pada mata pelajaran Akidah Akhlak di MIMU Tulung Jaya Sukadana Lampung Timur.

\section{B. KAJIAN TEORI}

Menurut Rusman "kontekstual merupakan proses dalam rangka membentuk siswa aktif dan dapat memaksimalkan kemampuannya, sehingga siswa dapat

\footnotetext{
${ }^{1}$ UU Ri. Nomor. 20 Tentang SISDIKNAS, (Bandung: Citra Umbara. 2003), hlm. 7
}

Vol. 1 No. 2 Oktober 2018

AL - MUDARRIS homepage: http://e-journal.staima-alhikam.ac.id/index.php/almudarris/index 
menerapkan konsep yang telah di pelajarinya dalam kehudapan mereka sehari hari secara nyata". 2

Pembelajaran CTL merupakan suatu proses pembelajaran holistik yang berjuang untuk membelajarkan peserta didik dalam memahami materi dan dapat mengkaitkan materi dengan kehidupannya baik kehidupan pribadi, agama, sosial, ekonomi, maupun cultural. $^{3}$ pembelajaran CTL membuat siswa dapat menghubungkan antara pengetahuan dan keterampilan yang diperoleh siswa kaitkan dengan kehidupannya sehari hari secara nyata sehingga siswa menjadi siswa yang aktif dan mandiri dalam pembelajaran di kelas, dimana siswa dituntut untuk mencari sendiri pengetahuan pembelajaran melalui pengalamannya dalam kehidupan seharihari.

Menurut Rusman dalam pembelajaran kontekstual guru harus melakukan tujuh prinsip, yaitu: Konstruktivisme (constructivism), Menemukan (Inqury), Bertanya (Questioning), Masyarakat Belajar (Learning Community), Pemodelan (Modelling),Refleksi (Reflection) dan Penilaian Sebenrnya (Authentic Assessment). ${ }^{4}$

Inti dari pembelajaran dengan menerapkan pendekatan CTL yaitu terjadi transfer belajar dimana siswa belajar dari kehidupan sendiri mereka sehari-hari bukan dari pemberian orang lain keterampilan dan pengetahuan semakin diperluas serta penting bagi siswa untuk mengetahui gunanya siswa tersebut belajar.

Hasil belajar siswa terhadap pelajaran Akidah Akhlak merupakan kemampuan siswa untuk memahami konsep yang diberikan, dalam hal ini akan terlihat dari hasil tes pelajaran Akidah Akhlak yang diujikan. Pembelajaran dikatakan berhasil jika pengetahuan siswa meningkat dari hasil sebelumnya.

Menurut Zainal Arifin "hasil belajar adalah hasil akhir dari kegiatan pembelajaran yang di tandai dengan guru memberi nilai kepada siswa dan siswa mendapat nilai dari pembelajaran yang sudah mereka lalui. Pada bagian lain, hasil belajar juga termasuk proses dalam pengembngan mental peserta didik". 5

lain:

Terdapat beberapa aspek yang berpengaruh terhadap hasil belajar, antara

1. Aspek kognitif adalah ranah yang mencakup kegiatan mental (otak). Menurut Bloom, usaha yang mencakup kerja otak merupakan termasuk ranah kognitif. ${ }^{6}$

2. Aspek afektif yaitu aspek yang mengenai sikap dan nilai. Ciri-cirinya dapat terlihat dari hasil tingkah laku siswa dalam kehidupan sehari-hari. ${ }^{7}$

3. Aspek psikomotorik dapat dilihat dari kemampuan dan keterampilan siswa dalam bertindak setelah memperoleh pembelajaran. ${ }^{8}$

Dalam pembelajaran Akidah Akhlak ketiga aspek di atas yaitu kognitif, afektif dan psikomotorik harus seimbang tidak hanya terpusat pada satu aspek saja yaitu aspek kognitif saja. akidah akhlak merupakan matapelajaran yang sangat penting bagi siswa terutama siswa sekolah dasar karena akidah akhlak memiliki

${ }^{2}$ Rusman, Model-Model Pemelajaran, (Jakarta: PT Raja Grafindo Persada,, 2011, hlm. 187.

${ }^{3}$ Nanang Hanafiah dan Cucu Suhana, Konsep Strategi Pembelajaran, (Bandung: PT Refika Aditama, 2010), hlm. 67.

${ }^{4}$ Rusman, Model-Model Pemelajaran,hlm. 193-197.

${ }^{5}$ Zainal Arifin, Evaluasi Pembelajaran, (Bandung: PT Remaja Rosda Karya,, 2011), hlm. 298.

${ }^{6}$ Anas Sudijono, Pengantar Evaluasi Pendidikan, (Jakarta: PT Raja Grafindo Pustaka, 2012), hlm.50

${ }^{7}$ Anas Sudijono, Pengantar Evaluasi Pendidikan, hlm.50

${ }^{8}$ Nana Sudjana, Penilaian Hasil Proses Belajar Mengajar, (Bandung:Remaja Rosdakarya, 2013), hlm. 30

Vol. 1 No. 2 Oktober 2018

AL - MUDARRIS homepage: http://e-journal.staima-alhikam.ac.id/index.php/almudarris/index 
fungsi untuk melatih siswa berperilaku sopan, santun, dan berbudi pekerti yang baik dalam kehidupannya sehari hari baik di sekolah maupun di masyarakat jika hal ini ditanamkan pada anak dasar maka dapat melahirkan generasi yang baik bagi bangsa karena memiliki mental yang bagus.

\section{METODE PENELIAN}

Penelitian ini termasuk dalam penelitian tindakan kelas (PTK). Prosedur penelitian tindakan kelas ini yang peneliti gunakan adalah model yang dikembangkan oleh Suharsimi Arikunto. Terdapat empat tahap dalam setiap siklusnya yang meliputi tahap perencanaan, tahap pelaksanaan, tahap pengamatan dan tahap refleksi. Adapun model yang dikembangkan oleh Arikunto tersebut adalah sebagai berikut; ${ }^{9}$.

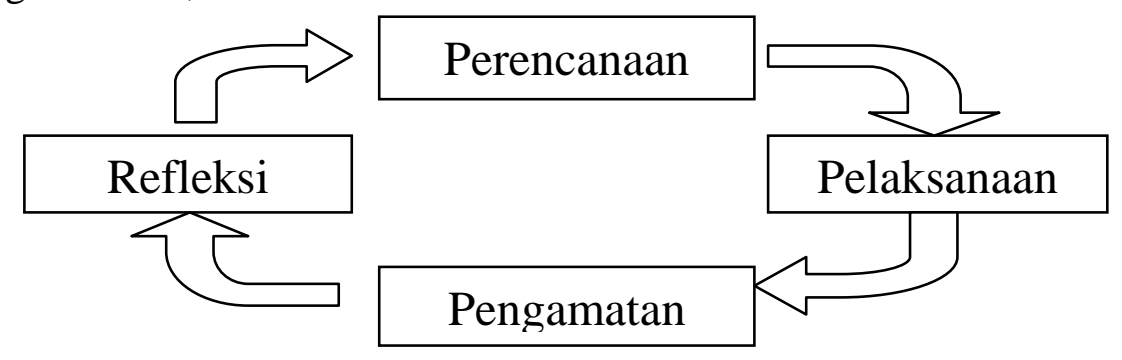

Sumber: Suharsimi Arikunto, et,al, PTK, hlm.16

Subjek dalam penelitian ini adalah siswa kelas V MIMU Tulung Jaya yang berjumlah 23 siswa, dengan rincian 13 siswa laki-laki dan 10 siswa perempuan. Teknik pengumpulan data yang peneliti gunakan dalam penelitian ini adalah menggunakan observasi, tes hasil belajar, wawancara dan dokumentasi. Observasi digunakan peneliti sebagai kolaborator untuk mengobservasi aktivitas siswa ketika mengikuti proses pembelajaran dan implementasi penggunaan pendekatan CTL yang dilakukan guru waktu proses belajar mengajar, karna menurut kunandar observasi merupakan aktivitas proses pengambilan data untuk melihat seberapa jauh pengaruh tindakan yang telah dilakukan sudah mencapai sasaran. ${ }^{10}$ Sehingga observasi sangat penting dalam penelitian ini. Tes hasil belajar digunakan peneliti untuk memperoleh data siswa mengenai hasil belajar sehubungan dengan pendekatan kontekstual dalam bentuk pemberikan tes, dimana tes dilakukan diakhir siklus dengan hasil belajar yang sesuai dengan KKM pada mata pelajaran Akidah Akhlak yaitu 70. Peneliti juga mengunakan tehnik Wawancara, wawancara adalah kegiatan tanya jawab yang menghasilkan informasi baik dilakukan secara langsung ataupun tidak langsung. Oleh karena itu wawancara digunakan untuk melengakapi data hasil observasi, sedangkan dokumentasi digunakan untuk melakukan analisis kurikulum untuk menentukan standar kompetensi dan kompetensi dasar dalam silabus dan rencana pelaksanaan pembelajaran yang akan digunakan dalam proses pembelajaran kepada siswa. Metode analisis data dalam penelitian ini penghitungannya menggunakan rumus statistik sederhana yaitu sebagai berikut:

a. Menentukan rata-rata nilai, digunakan rumus: ${ }^{11}$

\footnotetext{
${ }^{9}$ Suharsimi Arikunto, dkk, Penelitian Tindakan kelas, (Jakarta: Bumi Aksara, 2012), hlm. 16

${ }^{10}$ Kunandar, Penelitian Tindakan Kelas, (Jakarta: PT Rajawali Pers, 2011) hlm. 143

${ }^{11}$ Anas Sudijono, Pengantar Statistik Pendidikan, Cetakan ke XI, (Jakarta, PT Raja Grafindo Persada, 2001), hlm. 76.
}

Vol. 1 No. 2 Oktober 2018

AL - MUDARRIS homepage: http://e-journal.staima-alhikam.ac.id/index.php/almudarris/index 


$$
\mathrm{X}=\frac{\sum x}{N}
$$

b. Untuk menghitung prosentase, digunakan rumus: ${ }^{12}$

$P=x 100$

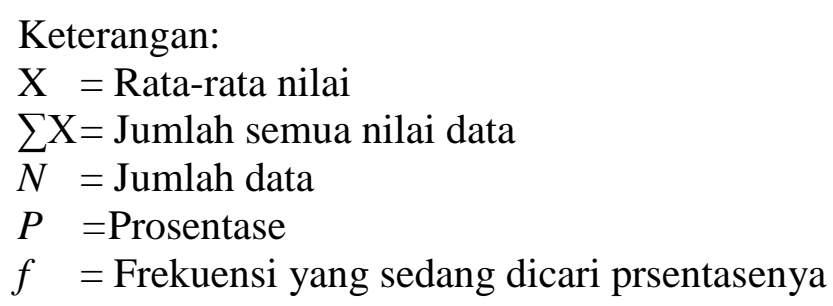

\section{TEMUAN DAN PEMBAHASAN}

Berdasarakan data observasi peneliti bahwa penerapan pendekatan CTL dapat meningkatkan hasil belajar siswa dalam pembelajaran akidah aklak hal ini terlihat dari siswa aktif ketika mengikuti kegiatan pembelajaran, dan ketika siswa sudah aktif dalam kegiatan pembelajaran maka hal itu dapat mempengaruhi hasil belajar siswa, hal ini terbukti dari hasil tes siswa pada setiap akhir siklus mengalami peningkatan yang signifikan.

Data hasil belajar siswa di siklus I diperoleh dari hasil tes yang diberikan pada siswa diakhir siklus. Setelah memberikan tes kepada siswa kelas V MIMU Tulung Jaya yang berjumlah 23 siswa maka di peroleh data nilai rata-rata siswa adalah 72, dan Jumlah siswa yang tuntas 15 siswa dari 23 siswa maka dapat dipersentasekan $65,22 \%$ tingkat ketuntasan pada siklus I dalam penerapan pembelajaran yang menerapkan pendekatan CTL pada mata pelajaran akidah akhlak siswa kelas V MIMU Tulung Jaya.

Hasil reflesksi peneliti dari siklus I menemukan bahwa masih banyak hasil belajar siswa yang masih belum mencapai KKM yang telah di tetapkan di MIMU Tulung Jaya yaitu 70, dan masih ada siswa yang masih malu-malu untuk bertanya kepada guru atau temannya ketika mereka kurang faham terhadap materi yang telah diajarkan, ada beberapa sisiwa kurang fokus ketika mengikuti kegiatan pembelajaran. sehingga pada sisklus I ketuntasan hasil belajar siswa masih belum mencapai target yang telah ditentukan yaitu sebesar $75 \%$. Oleh karean itu di lanjutkan pada siklus II.

Selanjutnya pada siklus II peneliti menemukan adanya peningkatan terhadap hasil belajar siswa kelas V MIMU Tulung Jaya pada mata pelajaran akidah akhlak, hal ini dilihat dari perolehan data hasil tes di akhir siklus yaitu diperoleh rata rata hasil belajar siswa kelas V MIMU Tulung Jaya adalah 77,30 dan tingkat ketuntasannya dapat di persentasekan sebesar 86,95\%, yaitu 20 siswa yang sudah mencapai KKM dan 3 siswa yang belum mencapai KKM. Dari hasil refleksi yang diperoleh dari siklus II ini masih ada siswa yang hasil belajarnya belum mencapai KKM akan tetapi keberhasilan hasil belajar siswa di siklus II sudah mencapai target yang telah di tentukan.

Masalah-masalah yang peneliti temukan pada siklus I hampir tidak peneliti temukan pada siklus II, hal ini di lihat dari siswa sudah mulai aktif mengikuti kegiatan pembelajaran tidak malu-malu lagi untuk bertanya baik kepada guru maupun kepada temannya metika mereka tidak faham dengan materi yang diajarkan, mulai fokus ketika mengikuti pelajaran dan meskipun beberapa siswa hasil

${ }^{12}$ Anas Sudijono, Pengantar Statistik Pendidikan, hlm. 40.

Vol. 1 No. 2 Oktober 2018

AL - MUDARRIS homepage: http://e-journal.staima-alhikam.ac.id/index.php/almudarris/index 
belajarnya belum mencapai KKM yang telah di tentukan oleh sekolah pada siklus II ini akan tetapi tingakat keberhasilannya lebih tinggi dari pada siklus I yaitu mengalami peningkatan $21,73 \%$. Dari hasil analisis data diatas maka dapat dinyatakan bahwa penerapan pendekatan CTL dalam pembelajaran akidah akhlak dapat meningkatkan hasil belajar siswa kelas V MMU Tulung Jaya Sukadana Lampung Timur.

\section{E. KESIMPULAN}

Berdasarkan hasil temuan dan pembahasan maka dapat diambil sebuah kesimpulan bahwa penerapan pendekatan CTL dalam pembelakaran akidah akhlak di kelas V MIMU Tulung Jaya terjadi peningkatan hasil belajar siswa, hal ini dapat dilihat pada setiap siklusnya, persentase siswa yang tuntas belajar pada siklus I sebesar 65,22\% yaitu berjumlah 15 siswa dan siklus II sebesar 86,95\% yaitu berjumlah 20 siswa dan mengalami peningkatan 21,73\%. Maka penerapan pendekatan CTL dapat meningkatkan hasil belajar siswa pada mata pelajaran akidah akhlak siswa kelas V MIMU Tulung Jaya sukadana lampung timur

\section{F. DAFTAR PUSTAKA}

Anas Sudijono. Pengantar Evaluasi Pendidikan. Jakarta: PT Raja Grafindo Pustaka. 2012.

Anas Sudijono. Pengantar Statistik Pendidikan. Jakarta: PT Raja Grafindo Persada. 2001

Kunandar. Penelitian Tindakan Kelas. Jakarta: PT Rajawali Pers. 2011

Nana Sudjana. Penilaian Hasil Proses Belajar Mengajar. Bandung: Remaja Rosdakarya. 2013

Nanang Hanafiah dan Cucu Suhana. Konsep Strategi Pembelajaran. Bandung: PT Refika Aditama. 2010

Rusman. Model-Model Pemelajaran.Jakarta: PT Raja Grafindo Persada. 2011

Suharsimi Arikunto, dkk. Penelitian Tindakan kelas. Jakarta: Bumi Aksara, 2012

UU Ri. Nomor. 20 Tentang SISDIKNAS. Bandung: Citra Umbara. 2003

Zainal Arifin. Evaluasi Pembelajaran. Bandung: PT Remaja Rosda Karya, 2011

Vol. 1 No. 2 Oktober 2018

AL - MUDARRIS homepage: http://e-journal.staima-alhikam.ac.id/index.php/almudarris/index 